Wulandari, et al/Jurnal Ekonomi Syariah Teori dan Terapan Vol. 6 No. 7 Juli 2019: 1385-1394; PERAN PEMBIAYAAN AKAD QARDHUL HASAN TERHADAP KESEJAHTERAAN PEDAGANG (STUDI KASUS:PENERIMA PROGRAM PINJAMAN BEBAS RIBA YAYASAN ROMBONG SEDEKAH)

\title{
PERAN PEMBIAYAAN AKAD QARDHUL HASAN TERHADAP KESEJAHTERAAN PEDAGANG (STUDI KASUS: PENERIMA PROGRAM PINJAMAN BEBAS RIBA YAYASAN ROMBONG SEDEKAH)'
}

\author{
Wahyu Tri Wulandari \\ Departemen Ekonomi Syariah-Fakultas Ekonomi dan Bisnis-Universitas Airlangga \\ Email:wahyu.tri-13@feb.unair.ac.id
}

Sunan Fanani

Departemen Ekonomi Syariah-Fakultas Ekonomi dan Bisnis-Universitas Airlangga Email: sunan-f@feb.unair.ac.id

\begin{abstract}
:
This study examines the role of qardhul hasan contract financing through a free loan program on Rombong Sedekah Foundation Jombang whether to improve the prosperity of super micro traders. The qardhul hasan contract is a contract whereby the borrower is not required to pay anything but the loan capital, but the borrower is allowed to give a portion of the profits to the lender in the form of a gift or grant but on one condition there is no agreement in advance. This research is a descriptive qualitative research by interviewing 10 informants. This study shows that the qardhul hasan contract on the riba free loan program has an impact in improving the welfare of the traders, and based on the indicators of maqashid shariah the traders have felt the impact of changes in their lives, that is to worship 5 days of worship, to receive proper education, responsible to their offspring, fulfilling the needs of the inner and outer by following the study conducted by the foundation, and experiencing an increase in income since following the free loan program, in addition they also no longer borrow to loanen borrowers or racially.
\end{abstract}

Keywords: Qardhul Hasan, foundation, welfare, and Maqashid Shariah

\section{PENDAHULUAN}

Pada era global saat ini, kemiskinan masih menjadi ancaman besar terhadap kualitas pembanngunan di Indonesia. Padahal dari segi kuantitatis, berdasarkan data Badan Pusat Statistik jumlah angka kemiskinan di Indonesia menurun. Hasil perhitungan BPS menunjukkan jumlah penduduk miskin pada periode Maret 2015 hingga Maret 2017 menurun dari 28,59 juta jiwa menjadi 27,77 juta jiwa (Badan Pusat Statistik, 2017: 113). Namun efektifitas penanganan kemiskinan di Indonesia masih sangatlah kurang, di jalanan masih banyak ditemui anak jalanan atau tuna wisma. Dari fenomena tersebut dapat dikatakan jika kemiskinan di Indonesia menjadi masalah yang sangat penting.

Suparlan (1984) dalam Pratama (2014) mendefinisikan bahwa kemiskinan adalah keadaan serba kekurangan harta dan benda berharga yang diderita oleh seseorang atau sekelompok orang yang hidup dalam lingkungan serba miskin atau kekurangan modal, baik dalam pengertian uang, pengetahuan, kekuatan sosial, politik, hukum, maupun akses terhadap fasilitas pelayanan umum, kesempatan berusaha dan bekerja.

Kemiskinan menyebabkan dampak yang sangat merugikan seluruh

\footnotetext{
1 Jurnal ini merupakan bagian dari skripsi Wahyu Tri Wulandari NIM 041311433056 yang diuji pada tanggal 19 Juli 2018.
} 
Wulandari, et al/Jurnal Ekonomi Syariah Teori dan Terapan Vol. 6 No. 7 Juli 2019: 1385-1394; PERAN PEMBIAYAAN AKAD QARDHUL HASAN TERHADAP KESEJAHTERAAN PEDAGANG (STUDI KASUS:PENERIMA PROGRAM PINJAMAN BEBAS RIBA YAYASAN ROMBONG SEDEKAH)

masyarakat Indonesia, yang pertama adalah terbatasnya akses bagi masyarakat miskin untuk mendapatkan pendidikan, jasa kesehatan, rumah layak huni, informasi, hukum, dsb. Hal tersebut dikarenakan rakyat miskin lebih mendahulukan untuk membeli kebutuhan bahan pokok daripada untuk sekolah. Dengan tidak bersekolah maka akses untuk mendapatkan pekerjaan yang layak akan sangat terbatas, dimana hal tersebut menyebabkan rakyat miskin akan selalu dalam kondisi miskin seumur hidup.

Kedua, kemiskinan dapat menyebabkan meningkatnya tindakan kriminalitas. Saat seseorang sedang dalam kondisi miskin, tidak memiliki pekerjaan, dan tidak berpendidikan maka orang tersebut akan cenderung melakukan tindakan kriminal demi mendapatkan vang untuk memenuhi kebutuhan pokoknya. Yang ketiga dan terakhir kemiskinan berdampak pada kurangnya solidaritas sosial.

Kemiskinan menyebabkan semakin langkanya solidaritas sosial di antara masyarakat karena semakin kuatnya himpitan hidup dan banyaknya tuntutan kebutuhan, akhirnya sifat kebersamaan dan kegotong-royongan yang selama ini telah terjalin hanya menjadi retorika saja.

"Sesungguhnya Allah itu telah menyediakan rizkiku tertelak di bawah tombakku" (HR. Ahmad). Dengan teramat jelas Allah SWT dan Rasul-Nya memerintahkan umatnya untuk bekerja. Bekerja adalah sebuah ibadah, maka dari itu bekerja adalah wajib hukumnya bagi umat Islam. Dalam Islam, bekerja bukan hanya untuk memenuhi kebutuhan hidupnya saja tetapi juga untuk manafkahi keluarganya. Hal tersebut bertujuan untuk menghindarkan masyarakat dari kemiskinan dan demi mencapai kesejahteraan.

Islam menekankan pentingnya setiap individu untuk memperhatikan dan mencapai kesejahteraan dalam hidupnya, kesejahteraan dapat diperoleh dengan cara mencapai kemaslahatan. Kemaslahatan secara sederhana diartikan sesuatu yang baik dan dapat diterima oleh akal sehat (Kara, 2012). Kemaslahatan merupakan sebuah konsep yang berangkat dari tujuan utama syariat Islam yang dikenal sebagai maqashid syariah. Menurut As-Syatibi, orientasi utama dari maqashid syariah adalah memberikan perlindungan dan proteksi terhadap lima hal, yaitu agama, diri, keturunan, akal, dan harta. Sedangkan kesejahteraan menurut Al-Ghazali dalam Syahrovi (2012) tolak ukur kesejahteraan adalah pada konsep maslahat atau utilitas (kebaikan bersama). Kesejahteraan dari suatu masyarakat tergantung kepada pencarian dan pemeliharaan lima tujuan dasar. Tujuan dasar maslahat: agama (aldien), hidup atau jiwa (nafs), keluarga atau keturunan (nasl), harta atau kekayaan (mal) dan intelek atau akal (aql). Dimana lima tujuan dasar tersebut adalah maqashid syariah. Jika lima unsur dari maqashid syariah sudah terpenuhi 
Wulandari, et al/Jurnal Ekonomi Syariah Teori dan Terapan Vol. 6 No. 7 Juli 2019: 1385-1394; PERAN PEMBIAYAAN AKAD QARDHUL HASAN TERHADAP KESEJAHTERAAN PEDAGANG (STUDI KASUS:PENERIMA PROGRAM PINJAMAN BEBAS RIBA YAYASAN ROMBONG SEDEKAH)

maka kesejahteraan umat akan meningkat.

Lembaga keuangan non-bank banyak jenisnya, salah satunya adalah lembaga keuangan mikro (LKM). Berdasarkan Undang-Undang Nomor 1 Tahun 2013 tentang Lembaga Keuangan Mikro, LKM adalah lembaga keuangan non-bank yang melakukan kegiatan usaha jasa pengembangan dan pemberdayaan masyarakat, baik yang didirkikan pemerintah atau masyarakat (ojk.go.id diakses pada 2 November 2017 pukul 20.03 WIB).

Lembaga keuangan non-bank dibagi menjadi dua macam, yaitu profit dan non profit. Menurut Widodo dan Kustiawan (2001: 3) dalam lembaga kevangan non profit adalah suatu lembaga yang menjalankan operasinya tidak berorientasi pada pencarian laba, namun tidak menutup kemungkinan jika lembaga tersebut dapat menghasilkan keuntungan juga, tetapi keuntungannya digunakan untuk menutup biaya operasional dari kegiatan utama lembaga tersebut.

Banyak komunitas yang saat ini yang telah beralih status menjadi yayasan. Di kota Jombang terdapat yayasan Rombong sedekah yang dahulu pada saat pertama kali didirikan masih berstatus sebagai komunitas. Yayasan yang telah berdiri sejak 3 tahun yang lalu ini memiliki tujuan yaitu mengantarkan amanah dari para pecinta sedekah atau para donatur hingga ke pelosok desa yang sangat membutuhkan. Rombong sedekah memiliki program-program yang sangat kental dengan nilai keislaman, kurang lebih ada 3 program, yaitu program memakmurkan masjid, program sosial dengan aksi pembangunan infrastruktur di desa terpencil, bedah rumah, bedah usaha, serta program ketiga adalah program ekonomi dengan aksi pinjaman bebas riba, dhuafa berdaya, serta wakaf produktif yang rencananya akan digunakan untuk pasar syariah pertama di Jombang. Programprogram tersebut dilaksanakan oleh para pengurus dan relawan Rombong Sedekah.

\section{Rumusan Masalah}

Bagaimanakah peran pembiayaan akad qardhul hasan dalam meningkatkan kesejahteraan pedagang penerima program pinjaman bebas riba di yayasan Rombong Sedekah.

\section{Tujuan Penulisan}

Adapun tujuan penulisan dilihat dari rumusan masalah pada skripsi di atas adalah:

Mengetahui peran pembiayaan akad qardhul hasan dalam meningkatkan kesejahteraan pedagang penerima program pinjaman bebas riba Rombong Sedekah.

\section{LANDASAN TEORI}

\section{Pembiayaan}

Menurut Ismail (Ahmad dan Ismail, 2011: 105) pembiayaan merupakan aktivitas bank syariah dalam menyalurkan dana kepada pihak lain selain bank 
Wulandari, et al/Jurnal Ekonomi Syariah Teori dan Terapan Vol. 6 No. 7 Juli 2019: 1385-1394; PERAN PEMBIAYAAN AKAD QARDHUL HASAN TERHADAP KESEJAHTERAAN PEDAGANG (STUDI KASUS:PENERIMA PROGRAM PINJAMAN BEBAS RIBA YAYASAN ROMBONG SEDEKAH)

berdasarkan prinsip syariah. Penyaluran dana dalam bentuk pembiayaan tersebut didasarkan pada rasa percaya dari pemilik dana pada pengguna dana bahwa dana dalam bentuk pembiayaan tersebut pasti akan dikembalikan. Penerima dana wajib mengembalikan pembiayaan dalam waktu yang telah ditentukan sesuai dengan akad pembiayaan.

Pembiayaan juga dapat diartikan sebagai pendanaan yang diberikan oleh suatu pihak kepada pihak lain untuk mendukung investasi yang telah direncanakan, baik dilakukan sendiri maupun oleh suatu lembaga. Dengan kata lain, pembiayaan adalah pendanaan yang dikeluarkan untuk mendukung investasi yang telah direncanakan.

Sedangkan menurut Umam (Umam dan Utomo, 2016: 205) pengertian pembiayaan adalah: penyediaan dana atau tagihan yang dipersamakan dengan berupa-berupa yaitu transaksi bagi hasil dalam bentuk mudharabah dan musyarakah, transaksi sewa menyewa dalam bentuk ijarah atau sewa beli dalam bentuk ijarah muntahiyah bit tamlik, transaksi jual beli dalam bentuk piutang murabahah, salam dan istishna', transaksi pinjam meminjam dalam bentuk piutang dan qardh dan transaksi sewa menyewa jasa dalam bentuk ijarah untuk transaksi multi jasa, berdasarkan persetujuan atau kesepkatan antara Bank Syariah dan/atau unit syariah (UUS) dan pihak lain yang mewajibkan pihak-pihak yang dibiayai dan/atau diberi fasilitas dana untuk mengembalikan dana tersebut setelah jangka waktu tertentu dengan imbalan Ujrah, tanpa imbalan atau bagi hasil.

Pembiayaan dalam perbankan Syariah menurut Al-Harran (1999) dalam Ascarya $(2007,122)$ dapat dibagi menjadi tiga.

a. Return bearing financing, yaitu bentuk pembiayaan yang secara komersial menguntungkan ketika pemilik modal mau menganggung

resiko kerugian dan nasabah juga memberikan keuntungan.

b. Return free financing, yaitu bentuk pembiayaan yang ditujukan untuk menbantu orang yang membutuhkan dan tidak mencari keuntungan sedikitpun.

c. Charity financing, yaitu pembiayaan yang ditujukan untuk orang miskin atau orang yang sedang terkena musibah, sehingga tidak ada klaim terhadap pokok dan keuntungan.

\section{Pembiayaan Akad Qardhul Hasan}

Menurut Subagyo $(2015,52)$ akad qardhul hasan disebut juga dengan pinjaman kebajikan, yang artinya adalah: meminjamkan harta kepada orang lain tanpa mengharapkan imbalan. Dalam literatur Figh, qardh dikategorikan sebagai aqd tathawu yaitu akad saling membantu dan bukan transaksi komersial.

Dalam rangka mewujudkan tanggungjawab sosial, Lembaga Kevangan Syariah dapat memberikan 
Wulandari, et al/Jurnal Ekonomi Syariah Teori dan Terapan Vol. 6 No. 7 Juli 2019: 1385-1394; PERAN PEMBIAYAAN AKAD QARDHUL HASAN TERHADAP KESEJAHTERAAN PEDAGANG (STUDI KASUS:PENERIMA PROGRAM PINJAMAN BEBAS RIBA YAYASAN ROMBONG SEDEKAH)

fasilitas yang disebut Al- Qardhul Hasan, yaitu penyediaan pinjaman dana kepada pihak yang layak untuk mmendapatkannya. Secara syariah peminjam hanya berkewajiban membayar kembali pokok pinjamannya walaupun syariah membolehkan peminjam untuk memberikan imbalan sesuai dengan keikhlasannya, tetapi lembaga Kevangan pemberi qardh tidak diperkenankan untuk meminta imbalan apapun.

Peminjam dana menyediakan tenaga untuk mengelola usaha dan LKS menyerahkan modal sebagai investasi. Modal yang diserahkan dalam qardh berasal dari dana ekstern dan bukan dari dana LKS sendiri. Dana qardhul hasan diperoleh dari dana kebajikan seperti: zakat, infak, sedekah, bantuan dari pihak lain, dan dana lainnya. Pinjaman qardh sebagai produk pelengkap untuk memenuhi kebutuhan dana yang mendesak atau untuk memenuhi kebutuhan lain yang tidak bersifat komersil. Bila terdapat keuntungan maka keuntungan $100 \%$ dinikmati oleh peminjam dana, tidak dibagi hasilkan dengan LKS. Pada saat pembayaran atau jatuh tempo, maka nasabah mengembalikan $100 \%$ modal yang berasal dari LKS tanpa ada tambahan. (Ismail: 2014, 214-215).

Rukun akad qardhul hasan terdiri dari 4 yaitu, ada peminjam atau disebut juga Muqtarid, yaitu orang yang membutuhkan dana. Yang kedua Muqrid atau pemberi pinjaman dana atau disebut juga orang yang memiliki dana. Lalu ada objek akad, yaitu qardh atau dana. Yang terakhir adalah adanya serah terima atau ijab qabul.

Sedangkan syarat dari akad qardhul hasan ada dua, yaitu dana yang digunakan bermanfaat, jadi dana tersebut harus benar- benar digunakan untuk tujuan yang tepat, bukan sematamata untuk memenuhi hawa nafsu. Contohnya adalah untuk modal membuka suatu usaha, mencukupi kebutuhan pendidikan. Kedua adalah adanya kesepakatan keduabelah pihak. Jadi kedua belah pihak harus sama-sama menyetujui akad yang akan digunakan, tidak boleh ada satu pihak yang merasa dirugikan, kesepakatan tersebut haruslah bersifat adil sesuai dengan syarit Islam. Dalam akad tersebut, kesepakatannya pemberi dana tidak boleh mengambil keuntungan atas dana yang dipinjamkan, kecuali jika peminjam dengan sukarela memberi kelebihan dana atas keuntungan yang didapat. Peminjam juga harus mengembalikan dana sesuai dengan waktu yang disepakati.

\section{Kesejahteraan}

Berdasarkan Undang-undang no 11 tahun 2009, tentang Kesejahteraan Masyarakat, kesejahteraan masyarakat adalah kondisi terpenuhinya kebutuhan material, spiritual, dan sosial warga negara agar dapat hidup layak danmampu mengembangkan diri, 
Wulandari, et al/Jurnal Ekonomi Syariah Teori dan Terapan Vol. 6 No. 7 Juli 2019: 1385-1394; PERAN PEMBIAYAAN AKAD QARDHUL HASAN TERHADAP KESEJAHTERAAN PEDAGANG (STUDI KASUS:PENERIMA PROGRAM PINJAMAN BEBAS RIBA YAYASAN ROMBONG SEDEKAH)

sehingga dapat Melaksanakan fungsi sosialnya. Berdasarkan Undang-undang di atas dapat kita ketahui bahwa ukuran tingkat kesejahteraan dinilai dari kemampuan individu atau kelompok dalam usahanya untuk memenuhi kebutuhan material dan spiritual. Kebutuhan material dapat kita hubungkan dengan pendapatan yang akan mewujudkan kebutuhan sandang, pangan, papan, dan kesehatan. Sedangkan kebutuhan spiritual dapat kita hubungkan dengan pendidikan, keamanan dan ketentraman hidup.

Menurut Sherraden dalam Pusparini (2015) jumlah pendapatan dan konsumsi rumah tangga adalah gambaran yang tepat untuk dijadikan tolak ukur kesejahteraan. Kesejahteraan diasumsikan langsung sebagai sesuatu yang dihubungkan dengan konsumsi dan rumah tangga. Fokusnya pada level konsumsi, termasuk jaminan kesehatan, perumahan, bantuan keuangan langsung, pendidikan, dan bidang kesejahteraan sosial lainnya.

Pada intinya kesejahteraan mencakup tiga konsep, yang pertama kondisi kehidupan atau keadaan sejahtera, yakni terpenuhinya kebutuhan kebutuhan jasmani, rohani, dan sosial. Kedua adalah institusi, yaitu arena atau bidang kegiatan yang melibatkan lembaga kesejahteraan social dan berbagai profesi kemanusiaan yang menyelenggarakan usaha kesejahteraan sosial dan pelayanan sosial. Terakhir adalah aktivitas, yaitu suatu kegiatan atau usaha yang terorganisir untuk mencapai sejahtera.

Dalam agama Islam dianjurkan terciptanya kesejahteraan sosial dalam masyarakat, bahkan kesejahteraan sosial juga menjadi salah satu prinsip dasar dalam ajaran Islam. Salah satu bentuk perhatian Allah SWT adalah memberikan jaminan bahwa nabi Muhammad SAW merupakan sosok yang sengaja diutus sebagai rahmat yang mendatangkan kebaikan, kemaslahatan dan kesejahteraan bagi seluruh alam. Hal tersebut dijelaskan dalam Surat Hud ayat 6, yang berbunyi, "Dan tidak ada suatu binatang melata pun di bumi melainkan Allah-lah yang memberi rezekinya, dan Dia mengetahui tempat berdiam binatang itu dan tempat penyimpanannya. Semuanya tertulis dalam Kitab yang nyata" (QS. Hud: 6)

Penjelasan dari ayat di atas bahwa rejeki setiap manusia sudah diatur oleh Allah SWT. Sebagai manusia kita wajib mencari rejeki secara halal dengan cara berkerja sesuai perintah Allah SWT agar kita dapat memenuhi kebutuhan hidup kita dan menjesejahterakan diri sesuai ajaran Islam.

$$
\text { Menurut Pusparini (2015), }
$$

kesejateraan dalam pandangan ekonomi Islam didasarkan atas keseluruhan ajaran Islam tentang kehidupan di dunia ini. Islam menegaskan ada dua konsep spiritual serta mencakup individu maupun sosial. Maksudnya adalah kesejahteraan diukur 
Wulandari, et al/Jurnal Ekonomi Syariah Teori dan Terapan Vol. 6 No. 7 Juli 2019: 1385-1394; PERAN PEMBIAYAAN AKAD QARDHUL HASAN TERHADAP KESEJAHTERAAN PEDAGANG (STUDI KASUS:PENERIMA PROGRAM PINJAMAN BEBAS RIBA YAYASAN ROMBONG SEDEKAH)

ketika seseorang dapat menjalankan habluminnallah dan habluminannas.

Habluminnallah adalah ketika kebutuhan material kita terpenuhi dan hubungan kita dengan sesama manusia berjalan dengan baik. Sedangkan habluminannas adalah ketika kebutuhan spiritual kita yaitu hubungan kita dengan Allah SWT tercipta dengan baik, sebagai contoh kita senantiasa beribadah untuk bekal kesejahteraan kita di akhirat nanti.

Kesejahteraan di dunia maupun di akhirat, sebab manusia tidak hanya hidup di dunia saja tetapi juga di akhirat. Jika kondisi ideal ini tidak dapat dicapai maka kesejahteraan di akhirat tentu lebih diutamakan. Maksudnya adalah jika kehidupan seseorang di dunia ini tidak sejahtera walaupun sudah berusaha semampunya, maka kita dianjurkan untuk senantiasa beribadah dan mendekatkan diri kepada Allah SWT.

$\mathrm{Hal}$ itu dilakukan dengan cara mengesampingkan kepentingan duniawi dan mendahulukan kepentingan di akhirat agar kita mendapat kesejahteraan di akhirat kelak.

Al-Ghazali mengungkapkan bahwa kesejahteraan suatu masyarakat hanya akan terwujud jika memelihara kelima tujuan dasar, yaitu agama, jiwa, akal, harta, dan keturunan. Kunci dari terpenuhinya kelima hal di atas terletak pada terpenuhinya tiga hal kebutuhan manusia, yaitu daruriyat seperti makanan, pakaian, dan rumah. Kedua adalah hajiyat yang dapat diperoleh dari kesenangan, dan yang terakhir adalah tahsiniyat atau sesuatu yang bersifat mewah.

a. Agama: Agama Islam adalah agama yang ajarannya mencakup setiap segi kehidupan. Semuanya telah diatur dan tertulis dengan baik dalam AlQuran. Sehingga dapat dikatakan bahwa agama adalah sumber pedoman seseorang dalam melakukan sesuatu. Agama dapat kita jaga dengan cara memenuhi ibadah sholat 5 waktu secara rutin, puasa, zakat, dan sedekah.

b. Jiwa: Kebutuhan akan jiwa dapat dilihat dari terpenuhinya kebutuhan sehari-hari seperti makan, minum, pakaian, dan tempat tinggal, atau kebutuhan dasar yang menunjang keberlangsungan hidup seseorang. Pemenuhan akan jiwa tidak semata- mata hanya pada konteks badan saja, tetapi juga kebutuhan spiritual juga ikut dalam andil. Contohnya adalah melakukan pengajian.

c. Akal: Manusia membutuhkan ilmu untuk memahami apa yang terjadi disekitar mereka. Selain itu, Allah memerintahkan umatnya untuk mencari ilmu. Dengan ilmu pengetahuan, seseorang dapat memecakan masalah dengan baik. Misalnya saja sekolah, ikut pengajian.

d. Keturunan: Keturunan dapat diartikan juga dengan menjaga kehormatan. Melakukan pernikahan secara sah 
Wulandari, et al/Jurnal Ekonomi Syariah Teori dan Terapan Vol. 6 No. 7 Juli 2019: 1385-1394; PERAN PEMBIAYAAN AKAD QARDHUL HASAN TERHADAP KESEJAHTERAAN PEDAGANG (STUDI KASUS:PENERIMA PROGRAM PINJAMAN BEBAS RIBA YAYASAN ROMBONG SEDEKAH)

untuk menghindari zina, dan agar memiliki keturunan yang tentunya harus diimbangi dengan bekal kualitas ilmu dan spiritual. Anak mampu sekolah secara layak juga dianggap salah satu kriteria untuk mendapatkan kualitas keturunan yang baik.

e. Harta: Harta merupakan salah satu kebutuhan yang sangat penting dan dibutuhkan manusia untuk memenuhi kebutuhan hidup. Dengan adanya harta, tingkat kebutuhan manusia dapat terpenuhi sesuai dengan tingkatan tertentu. Selain itu untuk memenuhi kebutuhan dasar manusia, harta juga diperlukan untuk melakukan zakat, infaq, dan sedekah.

\section{METODOLOGI PENELITIAN}

Penelitian ini menggunakan metode kualitatif. Metode kualitatif merupakan bagian dari proses pengetahuan yang dapat dianggap sebagai produk sosial dan juga proses sosial. Pengetahuan sebagai sebuah proses setidaknya memiliki tiga prinsip dasar yakni empirisisme yang berpangku pada fakta dan data, objektivitas dan kontrol (Singleton, dkk dalam Somantri, 2005).

Penelitian ini menggunakan pendekatan kualitatif, dikarenakan tujuan utama dari penelitian ini adalah adalah untuk menjelaskan perilaku, bukan untuk menggambarkan dan merumuskannya dalam angka. Penelitian ini memiliki upaya untuk memahami sesuatu dibalik fenomena secara kompleks serta ditujukan agar mendapatkan suatu gambaran apakah pembiayaan qardhul hasan berperan dalam meningkatkan kesejahteraan pedagang penerima program Pinjaman Bebas Riba. Peneliti memiliki peran yang sangat penting untuk mendapatkan gambaran secara kompleks, khususnya dalam pengumpulan data dan peneliti akan menggunakan multi sumber bukti untuk mendapatkan gambaran yang lengkap tentang qardhul hasan dalam meningkatkan kesejahteraan pedagang melalui program Pinjaman Bebas Riba di yayasan Rombong Sedekah.

\section{HASIL DAN PEMBAHASAN}

Qardhul hasan merupakan perjanjian pinjaman untuk tujuan sosial dengan memberikan pinjaman kepada mereka yang tergolong lemah dalam ekonomi. menurut Perwataatmadja dan Antonio $(1992,33)$ qardhul hasan adalalah suatu pinjaman lunak yang diberikan atas dasar kewajiban sosial dimana si peminjam tidak dituntut untuk megembalikan apapun kecuali modal pinjaman. pinjaman qardhul hasan yang diterapkan oleh Rombong Sedekah melalui program pinjaman bebas riba memerikan peluang usaha bagi pedagang super mikro yang ingin mengembangkan usahanya.

Pinjaman qardhul hasan tersebut memang dapat membantu para pedagang yang sedang membutuhkan suntikan dana sesuai dengan tujuan 
Wulandari, et al/Jurnal Ekonomi Syariah Teori dan Terapan Vol. 6 No. 7 Juli 2019: 1385-1394; PERAN PEMBIAYAAN AKAD QARDHUL HASAN TERHADAP KESEJAHTERAAN PEDAGANG (STUDI KASUS:PENERIMA PROGRAM PINJAMAN BEBAS RIBA YAYASAN ROMBONG SEDEKAH)

program pinjaman bebas riba. Pedagang tersebut tidak hanya diberi dana begitu saja tetapi juga dilatih untuk bersikap mandiri sehingga bertanggung jawab pada kewajibannya dan bekerja keras semaksimal mungkin. Tetapi yang ditemui di lapangan tidak semua pedagang merupakan pedagang yang amanah dan bertanggung jawab. Dari 8 sample yang diambil, terdapat 4 sample pedagang yang masih mengalami macet sedekah atau macet membayar angsuran. Alasannya pun beragam, dari mulai keluarga yang sakit, mengalami penurunan pendapatan, dan ada pula pedagang yang memang digolongkan sebagai pedagang bakhil yaitu mereka yang masih meminjam kepada rentenir sehingga mengutamakan pembayaran kepada rentenir dari pada kepada Rombong Sedekah.

Dalam konsep maqashid syariah terdapat 5 indikator yang dijadikan tolak ukur, yaitu agama, jiwa, akal, keturunan dan harta. Tujuh dari delapan pedagang yang telah diwawancarai oleh penulis mengaku hidupnya sudah sejahtera. Menurut penuturan mereka, para informan telah merasa sejahtera jika mereka dapat memenuhi kebutuhan sehari-hari dan menghidupi keluarga mereka. Namun hal tersebut tidak dapat dijadikan alasan bahwa hidup mereka telah sejahtera. Berikut adalah analisis penerapan maqashid syariah sebagai tolak ukur kesejahteraan pedagang penerima pinjaman bebas riba di Yayasan
Rombong Sedekah.

Pertama adalah indikator agama. Agama Islam adalah agama yang ajarannya mencakup setiap segi kehidupan. Semuanya telah diatur dan tertulis dengan baik dalam Al-Quran. Sehingga dapat dikatakan bahwa agama adalah sumber pedoman seseorang dalam melakukan sesuatu. Wajib hukumnya bagi umat Islam untuk selalu menjaga agamanya. Agama dapat kita jaga dengan cara memenuhi ibadah sholat 5 waktu secara rutin, zakat, sedekah, dan mengikuti pengajian.

Kedua adalah indikator jiwa. Kebutuhan akan jiwa dapat dilihat dari terpenuhinya kebutuhan sehari-hari seperti makan, minum, pakaian, dan tempat tinggal, atau kebutuhan dasar yang menunjang keberlangsungan hidup seseorang. Dalam surat tersebut dijelaskan bahwa sebagai umat Islam, manusia wajib memenuhi kebutuhan sehari-harinya seperti makan dan minum agar tetap dapat bertahan hidup. Saat dalam keadaan sakit, manusia juga wajib pergi berobat untuk mendapat kesembuhan. Pemenuhan akan jiwa tidak semata-mata hanya pada konteks badan saja, tetapi juga kebutuhan spiritual juga ikut dalam andil. Contohnya adalah melakukan pengajian.

Ketiga adalah indikator akal. Manusia membutuhkan ilmu untuk memahami apa yang terjadi disekitar mereka. Selain itu, Allah memerintahkan umatnya untuk mencari ilmu. Dengan ilmu 
Wulandari, et al/Jurnal Ekonomi Syariah Teori dan Terapan Vol. 6 No. 7 Juli 2019: 1385-1394; PERAN PEMBIAYAAN AKAD QARDHUL HASAN TERHADAP KESEJAHTERAAN PEDAGANG (STUDI KASUS:PENERIMA PROGRAM PINJAMAN BEBAS RIBA YAYASAN ROMBONG SEDEKAH)

pengetahuan, seseorang dapat memecahkan masalah dengan baik.

Keempat adalah menjaga keturunan. Keturunan dapat diartikan juga dengan menjaga kehormatan. Melakukan pernikahan secara sah untuk menghindari zina, dan agar memiliki keturunan yang tentunya harus diimbangi dengan bekal kualitas ilmu dan spiritual. Anak mampu sekolah secara layak juga dianggap salah satu kriteria untuk mendapatkan kualitas keturunan yang baik.

\section{SIMPULAN}

Berdasarkan hasil wawancara dan bservasi data penelitian yang diterima peneliti meunjukkan bahwa 8 informan yakni penerima dana qardhul hasan pada program pinjaman bebas riba di Yayasan Rombong Sedekah telah mengalami perubahan pada kesejahteraan hidupnya. Perubahan tersebut antara lain:

1. Peningkatan Agama

2. Peningkatan Jiwa

3. Peningkatan Akal

4. Peningkatan Keturunan

5. Peningkatan Harta

Sebagian besar informan tersebut telah merasakan dampak peningkatan kesejahteraan dalam hidupnya jika dilihat menggunakan indikator Maqashid Syariah. Maka dari itu dapat dikatakan bahwa pinjaman qardhul hasan yang diberikan oleh Yayasan Rombong Sedekah melalui program pinjaman bebas riba telah mampu meningkatkan kesejateraan para pedagang tersebut.

\section{DAFTAR PUSTAKA}

Badan Pusat Statistik. 2017. Jumlah Penduduk Miskin di Indonesia Periode Maret 2015-Maret 2017 (Dalam Jiwa). Retrieved from www.bps.go.id

Pratama, Y. C. 2014. Analisis Faktor-Faktor yang Mempengaruhi Kemiskinan Di Indonesia. Esensi: Jurnal Bisnis dan Manajemen, 4(2).

Kara, M. 2012. Pemikiran Al-Syatibi tentang Maslahah dan Implementasinya dalam Pengembangan Ekonomi Syariah. Jurnal Assets, 2(2), 173-184.

Widodo, H., \& Kustiawan, T. 2001. Akuntansi \& Manajemen Keuangan Untuk Organisasi Pengelola Zakat: Institut Manajemen Zakat.

Umam, K., \& Utomo, S. B. 2016. Perbankan Syariah: Dasar-Dasar dan Dinamika Perkembangannya Di Indonesia. Jakarta: PT Raja Grafindo Persada.

Pusparini, M. D. 2015. Konsep Kesejahteraan Dalam Ekonomi Islam (Perspektif Maqasid AsySyari'ah). Islamic Economics Journal, 1 (1), 45-59. 